\title{
Occupational Dermatosis- A Neglected Entity
}

\author{
Charulatha K. S. ${ }^{1}$, Mamatha S. Kusagur ${ }^{2}$ \\ ${ }^{1}$ Department of Dermatology, JJMMC, Davangere, Karnataka, India. \\ ${ }^{2}$ Department of Dermatology, JJMMC, Davangere, Karnataka, India.
}

\section{ABSTRACT}

\section{BACKGROUND}

Skin is our primary interface with the external environment. Occupational dermatosis is defined as any pathological condition of the skin for which job exposure can be a major direct or contributory factor. The commonest is work-related contact dermatitis $(\sim 90 \%)$. The other $10 \%$ includes infections, urticaria, chemical burns, photodermatitis, cutaneous malignancies etc. It is not only a health problem but also an economic issue. Aim of the study was to examine the epidemiological and clinical characteristics of workers with occupational skin disease.

\section{METHODS}

Data on demography, age, sex, education, type of occupation, type of dermatosis, and possible etiological factor were collected based on a pre-tested, semi structured questionnaire. This is a cross-sectional study conducted in a tertiary care centre during the period of June 2017 to May 2018.

\section{RESULTS}

Incidence among males and females was almost the same and majority were from rural areas and had finished primary schooling. Mean age was between 25 to 44 years. Majority of patients were farmers and were having intertrigo, moniliasis, photodermatitis, or contact dermatitis. Contact dermatitis was the most common disease in our study, with cement being the most common causative factor in males and soaps/detergents in females.

\section{CONCLUSIONS}

To conclude, most of the patients were farmers as agriculture is one of the main occupations in our country and among the dermatoses, contact dermatitis was the most common in our study with cement being the most common causative factor among males.

\section{KEY WORDS}

Occupational Dermatoses
Corresponding Author: Dr. Charulatha K. S., \#34, Adhvaitha, $2^{\text {nd }}$ Main, Jyothi Layout, Behind Jyothi Kendriya Vidyalaya, Yelachenahalli, Bangalore-560078, Karnataka, India. E-mail: charulatha.sathish@gmail.com

DOI: $10.14260 / \mathrm{jemds} / 2020 / 316$

Financial or Other Competing Interests: None.

How to Cite This Article: Charulatha KS, Kusagur MS. Occupational dermatosis- a neglected entity. J. Evolution Med. Dent. Sci. 2020;9(17):1450-1453, DOI: 10.14260/jemds/2020/316

Submission 04-03-2020, Peer Review 14-04-2020, Acceptance 20-04-2020, Published 27-04-2020.

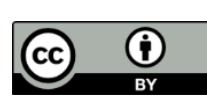




\section{BACKGROUND}

Skin is our primary interface with the external environment and in general, performs quite efficiently as a barrier against noxious chemicals or living organisms that are present in the external environment. Breakdown of this protective barrier due to different type of occupations can lead to development of work-related dermatosis. Occupational dermatosis is defined as any pathological condition of the skin for which job exposure can be shown to be a major direct or contributory factor. Occupational dermatoses account for approximately $30 \%-45 \%$ of all occupational diseases and are responsible for an estimated $25 \%$ of all lost workdays in the United States.[1] In Asia, the statistics regarding the magnitude of the problem are not available.

The commonest occupational dermatosis is work related contact dermatitis ( 90\%).[2] The other $10 \%$ includes infectious diseases such as candidal intertrigo/onychomycosis/butchers' wart etc., urticarial lesions, chemical burns, photo dermatitis, cutaneous malignancies etc.

\section{Classification of Occupational Dermatoses (OCD) ${ }^{[3]}$}

1. Due to Contact with Various Chemical Agents
a. Contact dermatitis.
b. Contact urticarial.
c. Chemical burns.
d. Occupational acne.
e. Occupational skin cancer.
f. Connective tissue disease.
g. Pigmentary changes.

2. Due to Contact with Various Physical Agents
a. Sun/ UV radiation: photo dermatosis.
b. Heat: miliaria, fungal infection.
c. Ionizing radiation: skin cancer.
d. Cold: frostbite.

3. Due to Various Biological Agents
a. Bacterial: impetigo, erysipelas.
b. Fungal: tinea corporis, tinea barbae, candidiasis, onychomycosis.
c. Viral: herpetic whitlow, Milker's nodules, butcher's warts.
d. Parasitic infection: scabies.

4. Due to Mechanical Agents
a. Friction: lichenification, melanosis, alopecia.
b. Pressure: urticarial.
c. Vibration induced scleroderma.
d. Nails: koilonychia, pitting, pigmentation, dystrophy.

In India, some of the major allergens causing occupation related contact dermatitis are, plants like parthenium and chrysanthemums, pesticides, cashew nuts, paddy, cement, etc. Occupational skin diseases affect workers of all ages in a wide variety of work settings such as - teaching profession, hairdressing, medical and dental departments, veterinary, agriculture, cleaning, printing, painting, construction, food preparation, industries and catering, etc.

These occupational dermatoses are not only a health problem but also an economic issue and loss because of this can be very huge. Management of these problems are important in patient's daily life. Level of physical and psychological disability and consequences of social relations due to this has to be addressed.

These skin diseases force many workers to change their jobs and those affected persons often experience severe impairment in their quality of life. They experience discrimination at workplace, and it may limit their career progression often.

The main goal of diagnosing and treating these patients who are suffering from such occupational dermatoses is to prevent them from becoming chronic in order to improve their health, quality of life and also reduce the economic burden which would have caused because of this.

\section{Objectives}

The objectives of the study were- to describe the patterns of diagnosis of occupational skin diseases, and also to examine the epidemiological and clinical characteristics of workers with occupational skin disease.

\section{METHODS}

This is a cross-sectional study conducted in Department of Dermatology, JJMMC (Bapuji Hospital and Chigateri District Hospital), Davangere during the period of June 2017 to May 2018. All clinically diagnosed occupational dermatoses cases i.e., those patients who have temporal relation with occupational exposure for their dermatoses, attending dermatology OPD from June 2017 to May 2018 were included in the study. Data on demography, age, sex, education, type of occupation, type of dermatosis and possible etiological factor were collected based on a pre-tested, semi structured questionnaire.

Diagnosis of occupational dermatoses was made on the basis of history and clinical examination where positive temporal relation with occupation and the development of dermatosis was present.

Structured questionnaire in our study had questions pertaining to their locality, age, sex, education, type of occupation, etc. and in that questionnaire, it was recorded whether the patient is from rural or urban area to know their demography. Age was divided into five groups for our convenience and those five groups were as follows; ten to 14 years, 15 to 25 years, 25 to 44 years, 45 to 64 years and 65 and above. Education of the patients were again grouped into five groups for our convenience and those are primary schooling, secondary schooling, under graduation, post-graduation and those who are uneducated.

MS Excel was used for data analysis and results are expressed in percentages and proportions. 


\section{RESULTS}

In our study, sociodemographic features of occupational dermatoses is as tabulated in the below table; Table 1. Total number of patients included in the study were 100, among which 53 were males and 47 were females with male to female ratio being 1.13. In the study, 78 out of 100 patients were from rural area and 22 of them were from urban area with rural to urban ratio being 3.54. Considering their education, 26 were uneducated, 34 and 31 had finished primary and secondary schooling respectively, six were undergraduates and three were postgraduates. In this study, there were none below the age group of 15 years, with three of them falling in the range of 15 to 24 years, 53 patients falling in the range of 25 to 44 years, 42 of them falling in the range of 45 to 64 years and only two of them were above 65 years of age.

Among the total of 100 occupational dermatoses cases in our study, 41 were farmers, 17 were housewives, 14 were coolies (construction workers), five were industrial workers, five were housemaids, four were teachers, two were hospital staffs, one was an officer and the rest 11 were included in others ' which included flower vendors/barbers/ railway track maintainers and milking.

In the study, 51 out of 100 patients had contact dermatosis (allergic/ irritant), 16 had candidal intertrigo, 18 had photo dermatosis (PMLE/phytophotodermatitis), seven had moniliasis, six had onychomycosis and two of them had chronic paronychia. In both males and females contact dermatitis was the most common occupational dermatosis but the causative or aggravating factor among them were different. Among males it was cement which was the most common causative factor for contact dermatoses and among females it was soaps and detergents. Other factors found to be causative factors for occupational contact dermatitis were flowers, chemical sprays, chalk powder, milk, parthenium, steel, rubber gloves, onion, diesel and aluminium in the descending order.

Among farmers, being the most common occupation found to be associate with occupation related dermatoses in this study (41 out of 100), most common dermatoses among these farmers was infections ( 19 patients out of 41 farmers) which included candidal intertrigo, onychomycosis and moniliasis in the descending order and it was correlated to excessive wet work exposure among these farmers. 16 out of 41 farmers had photo related dermatoses such as polymorphic light eruption (PMLE) and photo allergic dermatitis/photo contact dermatitis due to chronic sun exposure during their work hours in field. The rest six patients had contact dermatitis due to exposure to parthenium in their working environment and chemical spray which was used by these famers in their field.

Among housewives, which was the second most common group to be associated with occupation related dermatoses (17 out of 100), diagnosis made were contact dermatitis especially hand eczemas and fungal infections such as moniliasis, candidal intertrigo and onychomycosis in the descending order. Contact dermatitis or housewife's eczema being the most common occupational dermatoses among these housewives was majorly associated with exposure to soaps and detergents.

Among construction workers, all 14 patients were having contact dermatitis and associated causative factor for this was cement.
Among teachers, chalk powder was found to be the causative factor to cause contact dermatitis.

Among housemaids, fungal infection (moniliasis, candidal intertrigo and onychomycosis) was the most common disease associated in this study followed by contact dermatitis to soaps and detergents.

Among the two hospital staffs in this study, contact dermatitis was diagnosed and was correlated to the use of rubber gloves.

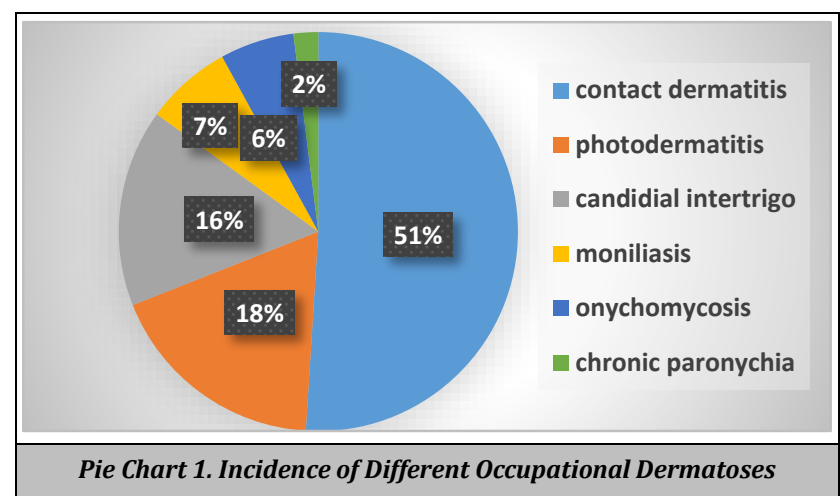

\begin{tabular}{|c|c|}
\hline Gender & 53 \\
Males & 47 \\
Females & \\
Education & 26 \\
Uneducated & 34 \\
Primary schooling & 31 \\
Secondary schooling & 6 \\
Under graduation & 3 \\
Post-graduation & 78 \\
Residence & 22 \\
Rural & \\
Urban & Nil \\
\hline Age (Years) & 3 \\
$10-14$ & 53 \\
$15-24$ & 42 \\
$25-44$ & 2 \\
$45-64$ & \\
$>65$ &
\end{tabular}

\section{DISCUSSION}

Occupational dermatoses is one of the major health problems with an estimated annual incidence of 1.89 million/ year.[4] Unlike the West, where a good notification systems exist for occupational dermatoses, Asian countries do not have an established system of reporting these diseases; hence data regarding epidemiology is scant. The incidence of various occupational dermatoses is determined by the degree of socioeconomic and industrial development in an area, resulting in a lot of geographical variation. ${ }^{[5]}$

According to our study, incidence among males and females was almost the same with slight male preponderance. We found that majority of patients were residing in rural area (78 out of 100 patients) with rural to urban ratio being 3.54 . Most of the patients in our study had finished primary and secondary schooling (34 and 31 patients respectively out of 100 patients) and one fourth of the patients were uneducated. Majority of them who were found to have occupational dermatosis were adults with no childhood cases being reported and a smaller number of cases belonging to adolescent and elderly age group. 
Among the 100 patients, most of them were agriculturists (41 patients), followed by housewives, coolie (construction workers), housemaids, industrial workers, teachers, skilled labours and an officer in descending order. Among all the diagnosis, contact dermatitis (allergic or irritant) was the most common disease encountered, among 51 patients, followed by photo dermatosis, candidal intertrigo, moniliasis, onychomycosis and chronic paronychia in descending order. (pie chart 1)

Diagnosis was solely based on history and clinical examination and confirmation of contact dermatitis with patch testing was not done and that remains one of the major drawbacks of this study.

\section{CONCLUSIONS}

To conclude, most of the patients were farmers as agriculture is one of the main occupations in our country. Educating these farmers regarding preventive measures and personal hygiene may reduce the burden of such occupational dermatoses. Among the dermatoses, contact dermatitis was the most common in our study with cement being the most common causative factor among males. Hence pre employment examination and education along with periodic examination of these workers may reduce the incidence and morbidity.

\section{REFERENCES}

[1] U.S. Department of Labor, Bureau of Labor Statistics. Occupational Injuries and Illnesses Counts, Rates and Characteristics, 1995. Washington, D.C.: U.S. Department of Labor, Bureau of Labor Statistics, 1998.

[2] Rustemeyer T, Elsner P, John SM, et al. Karneva's Occupational Dermatology. Springer-Verlag Berlin Heidelberg 2012. DOI 10.1007/978-3_8

[3] Jayashree R, Srinivas CR. Occupational dermatosis. Chap 23. Vol. 1. $4^{\text {th }}$ edn. IADVL 2015: p. 872-86.

[4] Leigh J, Macaskill P, Kuosma E, et al. Global burden of disease and injury due to occupational factors. Epidemiology 1999; 10(5):626-31.

[5] Bhatia R, Sharma VK. Occupational dermatoses: an Asian perspective. Ind J Dermatol Venereol Leprol 2017; 83(5):525-35. 